\title{
Disperse Ink-Jet Inks with UV-Absorbers as Active Agents for Digital Printing to Polyester and Polyamide Fibres
}

\section{Karanikas EK*, Nikolaidis NF}

Department of Industrial Chemistry and Chemical Technology, School of Chemistry, Aristotle University of Thessaloniki, GR54124, Thessaloniki, Greece

\section{Abstract}

Two UV-absorbers, Tinuvin 477-DW and Tinuvin 5333-DW were used as active agents in this work. These were added in two different amounts (1.0\% and $2.0 \%)$ in water-based disperse ink-jet inks. The surface tension, $\mathrm{pH}$, viscosity and conductivity of the prepared formulations were monitored over a period of 90 days in order to estimate the ink stability and the compatibility of the UV-absorbers with the ink constituents. The inks were used for ink-jet printing on paper, transfer printing on polyester and polyamide and thermostabilization. Wash light and rub fastness were evaluated on the printed samples. Color coordinates were measured. Qualitative determination of the active agents, adsorbed on the printed samples was made by using UV-Vis Spectroscopy.

Keywords: ink-jet ink, UV-absorber, digital printing, polyester, polyamide.

Copyright (C) 2020 The Author(s): This is an open-access article distributed under the terms of the Creative Commons Attribution 4.0 International License (CC BY-NC 4.0) which permits unrestricted use, distribution, and reproduction in any medium for non-commercial use provided the original author and source are credited.

\section{INTRODUCTION}

Ink-jet printing is one of the fastest growing of imaging technologies; showing benefits over the conventional printing methods of roller and flatbed screen printing. These benefits include economic production of small runs, just in time delivery, quick response to fashion demands, no stock holding of chemicals and printed fabrics, no chemical waste, as well as low energy and water consumption [1-3].

Textile digital printing emerged in the 1990s as a prototyping tool and a vehicle for printing small batches of fabric for niche market products and to produce advertising materials such as flags and banners [4].

Today the application areas of ink-jet printing cover the production of fashion apparel for men and women, sports and swimwear, home textiles such as curtains and sheets, automotive upholstery, flags and banners, T shirt, promotional material etc [5].

Most textile substrates can be digitally printed including polyester, cotton, silk and nylon. The classes of dyes used are the same as those used for conventional dyeing and printing, however careful selection is needed to meet the specific criteria for the production of digital printing inks [6].
The fastness requirements of digitally printed textiles depend on the final end use of the printed article and remain the same as those for the conventionally produced articles. These fastness requirements can be met by selecting the dyes and pigments from those already available for the conventional coloration of textiles but they have to undergo specific production procedures in order to meet critical parameters in terms of purity, solubility, particle size and suitability for the specific application needs of digital printing $[6,7]$.

Ink-jet inks must be carefully formulated to yield specific properties that enable optimum droplet formation within the fine nozzles of a printing head for application at high speed. Such properties are dependent upon the $\mathrm{pH}$, surface tension, viscosity, conductivity and particle size distribution of the ink. Furthermore, inks designed for the ink-jet printing of textile materials need to satisfy various fastness criteria namely wash, light and rubbing $[2,3,8]$.

Water-based ink-jet inks offer environmental advantages over their non-aqueous based counterparts, through reduced emissions of volatile organic compounds that are otherwise present in solvent-based formulations. With environmental considerations continuing to have ever-greater impact upon industry and legislation, textile producers have to carefully examine the environmental impact of the products used. 
Water-based inks contain, typically, 30-80\% water as a proportion of the total mass of the ink, together with a water miscible organic solvent such as a monohydric alcohol (methanol, ethanol, isopropanol), the colorant (e.g. disperse dye) and a surface active agent which, in the case of disperse dyes, acts as a dispersant for the dye in the aqueous medium $[8,9]$.

UV-absorbers have been utilized to protect polymeric materials from photodegradation caused by sunlight or ultra-violet rich artificial light. Recently, interest has developed in the application of UVabsorbers in the dyeing and printing of textile materials to protect their color from fading. High light fastness of dyed/printed materials is important especially for automobile colored upholstery, which can be exposed to direct sunlight and temperatures above $50^{\circ} \mathrm{C}$ [10].

Various commercial UV-absorbers, mainly of the benzophenone [10-12] and Benzotriazole [10, 11, 13] and less of other classes (benzoic acid esters, hindered amines) used directly for polyester [11, 13], woo1 [13], polyamide [10] and polypropylene [10] fibres caused a light fastness improvement ranging from 0 to 2 units of the blue standard scale [14] for various dyes. Nevertheless an investigation of light fastness improvement by adding UV-absorber for dyes of lower light fastness is also interesting, especially when these are of low cost, brightness, etc., or applied to fabrics for other uses. An improvement in light fastness has been achieved either by addition of a UV-abs in the ink-jet process.

In this study two UV-absorbers Tinuvin 477DW and Tinuvin 5333-DW was used as active agents. Tinuvin 477-DW is an aqueous UV-absorber dispersion developed for waterborne coatings. Based on a red shifted hydroxyphenyl-s-trizine chromophore, it is suited for coatings and substrates requiring strong UVA range wavelength protection. Its high heat stability and excellent photo-permanence provide superior UV stabilization and full fills the requirements of high performance industrial, decorative, and wood coatings. Tinuvin 477-DW is recommended for clear and light pigmented coatings in applications such as: Wood stains and varnishes, wood care products, waxes, Coatings on plastics (films, bottles, containers), Coatings on PC and PMMA sheets, panels, glasses, UV blocking varnishes on printed materials (paper, board, wood), Glass coatings (architectural glazing, packaging) and Adhesives and bonding layers. Tinuvin 477-DW is particularly suited for the protection of UVA range sensitive substrates, prints, or contents. It's very high thermo- and photo-stability and high water leaching resistance confer an extremely durable protection to coatings and coated substrates. Tinuvin 477-DW protects efficiently the color and appearance of natural and stained wood. It is also particularly suited for UV blocking varnishes on tinted or printed materials to prevent fading of the prints [15].

Tinuvin 5333-DW is an aqueous dispersion of a blend of UV absorbers (UVA) and a hindered amine light stabilizer for coatings, adhesives, sealants and printing inks. It was designed to meet high performance and durability requirements of exterior water-based industrial and architectural coatings including radiationcurable systems (UV, electron beam). Tinuvin 5333DW is based on high-performance UV absorbers and low-alkaline aminoether HALS blend, is excellent longterm performance (photo permanence), has high thermal stability, fully preserves dry-film properties such as, inherent color, transparency, gloss and other coating film properties such as water impermeability and blocking resistance, hardness and scratch resistance are not affected, stir-in product, easily mixes with water-based systems without applying high shear forces; disperses homogeneously without co-solvents or any other dispersion aids. Tinuvin 5333-DW is especially suitable for water-based acrylics and PUD dispersions with low to zero-voc requirement or where a traditional 2-(2-hydroxyphenyl) benzotriazole UV absorber needs to be upgraded. Tinuvin 5333-DW is suitable for wood coatings (joinery coatings, stains, deck finishes), vinyl coatings (displays, PVC liners, tarpaulins, floor tiles), plastic coatings (PC, PMMA, PET, sheets, films, packaging), coatings on glass (architectural glazing, packaging materials), architectural coatings, overprint varnishes over metal, board, paper, laminates, and adhesives and sealants [16].

The aim of this work is the preparation of stable disperses ink jet inks for digital printing applications with and without UV-absorbers as active agents. Physicochemical properties of the inks $\mathrm{pH}$, conductivity, surface tension and viscosity were studied. The inks were used for digital ink jet printing to polyester and polyamide samples. Fastness properties and colorimetric coordinates of the prints are also performed.

\section{Experimental Section \\ MATERIALS AND METHODS}

Double-Jersey $100 \%$ polyester fabric white $190 \mathrm{~g} / \mathrm{m}^{2}$ supplied by Grenter-Jersey AG (Switzerland) as well as nylon 6.6 (78F46, $1.69 \mathrm{dtexpf)}$ supplied by KYKE HELLAS were used. The dye CI Disperse Blue 60 (Serilene Brilliant Blue 2GN) were kindly supplied by Yorkshire Colors, Germany was used as a disperse dye (Figure 1). Commercial grade 2-propanol (Fluka) and ethylene glycol (Riedel-de-Haen, Germany) were used. Alcoospers LFD (KYKE HELLAS SA), a condensation product of formaldehyde-sulphonic acid sodium salt was used as dispersing agent. Tinuvin 477 DW and Tinuvin 5333-DW (Figure 1) were used as UV-absorbers. 
<smiles>COCCCn1c(=O)c2c(N)c3c(=O)c4ccccc4c(=O)c3c(N)c2c1=O</smiles>

\section{Disperse Blue 60}

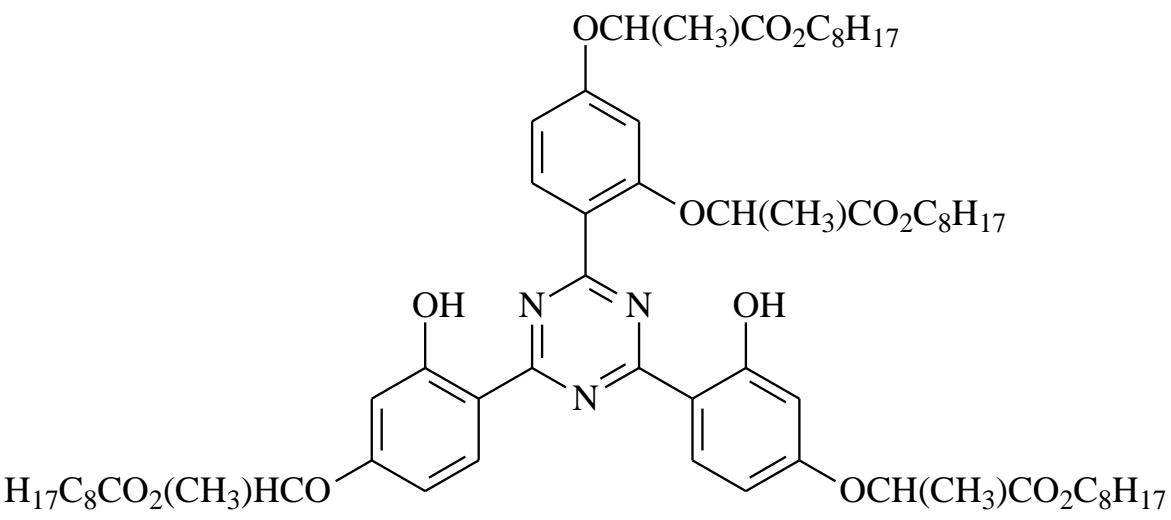

Tinuvin 477-DW<smiles>CC1CC(OC(=O)CCCCCCCCCC(=O)OC2CC(C)[NH2+]C(C)C2)CC(C)(C)N1</smiles>

Tinuvin 5333 DW

Fig-1: Structure of the dye and the UV-absorbers used

\section{Ink formulation}

In Table 1 the water-based ink formulations containing $2 \%$ w/v dye, $75 \%$ v/v $\mathrm{H}_{2} \mathrm{O}$, a mixture of 2propanol (IPA)/ethylene glycol (EG) $20 / 5 \mathrm{v} / \mathrm{v}$ as the miscible solvent, $0.05 \% \mathrm{w} / \mathrm{v}$ dispersing agent and various $\%$ amounts of aquaeous solution $10 \%$ of the two UV-absorbers are given. The reference formulation, without active agent, is also included (Table 1). The mixture of ingredients was homogenized for $10 \mathrm{~min}$ using a Sonicator UP100H homogenizer at room temperature. 
Table-1: Ink formulations prepared with and without active agent.

\begin{tabular}{|l|l|l|}
\hline \multirow{2}{*}{ No } & Active Agent \\
\cline { 2 - 3 } & $\mathbf{1 0 \%}$ w/v Tinuvin 477-DW \% v/v & $\mathbf{1 0 \%}$ w/v Tinuvin 5333-DW \% v/v \\
\hline 1.1 & - & - \\
\hline 1.2 & 1.0 & - \\
\hline 1.3 & 2.0 & - \\
\hline 1.4 & - & 1.0 \\
\hline 1.5 & - & 2.0 \\
\hline
\end{tabular}

\section{Surface tension conductivity, viscosity and $\mathrm{pH}$ measurements}

Surface tension measurements were made using a KSV Sigma 70 tensiometer fitted with a De Nouy platinum ring. Conductivity measurements were performed using a Crison Conductimeter Basic 30 and $\mathrm{pH}$ measurements were made using a WTW Microprocessor $535 \mathrm{pH}$ meter, viscosity measurements were made using a Viscostar plus+ $\mathrm{H}$ (Fungilab) viscometer. The above properties were measured at room temperature and atmospheric pressure for $1,7,14$, 30, 60 and 90 days for the inks containing the active agents Tinuvin 477-DW and Tinuvin 5333-DW and the reference ink.

\section{Ink-jet printing}

Printing was performed on paper, with a Canon iP7250 printer, followed by transfer printing on paper and then thermostabilization to polyester and polyamide fabric for $30 \mathrm{sec}$.

The printed samples were then rinsed in cold water and reduction cleared using a solution comprising $2 \mathrm{~g} / \mathrm{l}$ sodium dithionite and $1.5 \mathrm{~g} / \mathrm{l}$ sodium carbonate at $60^{\circ} \mathrm{C}$ using a liquor ratio of $20: 1$ for $20 \mathrm{~min}$. The reduction cleared samples were rinsed in cold water and allowed to dry in the open air.

\section{Fastness tests}

Wash fastness of the prints was carried out according to BS1006:1990CO2 test, light fastness was carried out according to BS1006:1990BO2 test, whereas dry and wet rub fastness was carried out according to ISO 105 X12 [14].

\section{Color measurements}

The reflectance values of the prints were measured using a Macbeth CE 3000 spectrometer under D65 illumination, 10 standard observer with UV and specular component included. The CIE1976 L*a*b*C* $\mathrm{H}^{*}$ coordinates and the K/S values were calculated from the reflectance values at the appropriate $\lambda \max (\lambda \max$ 680nm for Disperse Blue 60).
Identification and determination of the UVabsorbers adsorbed on the printed samples

Quantitative determination of the UV-absorber of the printed sample was made after extraction of the two active agents with polyethylene glycol 200 and measuring spectrophotometrically the extract at $363 \mathrm{~nm}$ ( $\lambda \max$ of Tinuvin 477-DW) and $360 \mathrm{~nm}(\lambda \max$ of Tinuvin 5333-DW). Four extraction cycles (1g sample in a liquor ratio $1: 10,30 \mathrm{~min}, 130^{\circ} \mathrm{C}$ for polyester and $98^{\circ} \mathrm{C}$ for polyamide) were carried out for the quantitative recovery of Tinuvin 477-DW and Tinuvin 5333-DW active agents from the fabric.

\section{RESULTS AND DISCUSSION Physical Properties of the Inks}

Monitoring a formulation over a period of time is a widely accepted method for evaluating dispersion stability $[5,8]$. In this study the surface tension, $\mathrm{pH}$, viscosity and conductivity of the formulations prepared were monitored over a period of 90 days for the digital printing inks containing the UV-absorbers Tinuvin 477DW and Tinuvin 5333-DW.

Figures 2, 3 show the $\mathrm{pH}$ values of the inks prepared with Disperse Blue 60 against time of storage. From the above figures can be concluded that the blue formulation without active agent 1.1 (Table 1) has slightly acid $\mathrm{pH}$. This is due to the fact that the blue dye has been milled and processed in acid environment. The addition of the UV-absorbers Tinuvin 477-DW and Tinuvin 5333-DW in the formulations 1.2 -1.5 causes a serious increase in $\mathrm{pH}$ values compared to the reference formulation 1.1 (without active agent) followed by small decrease over the period of storage time. This can be explained that the $\mathrm{pH}$ of both active agents have slightly alkaline character in the region of 8-9 due to the amino groups which contain in their molecules. The inks with the active agents are approaching the neutral region. Given that acceptable $\mathrm{pH}$ values for ink-jet inks are near the neutral region $(6.5-8.0)$ the formulations 1.2-1.5, with $\mathrm{pH}$ values 6.9-6.2 are in this area so they do not need correction as the reference ink with $\mathrm{pH}$ values $6-5.35$, which needs a slightly correction with buffer solution. 


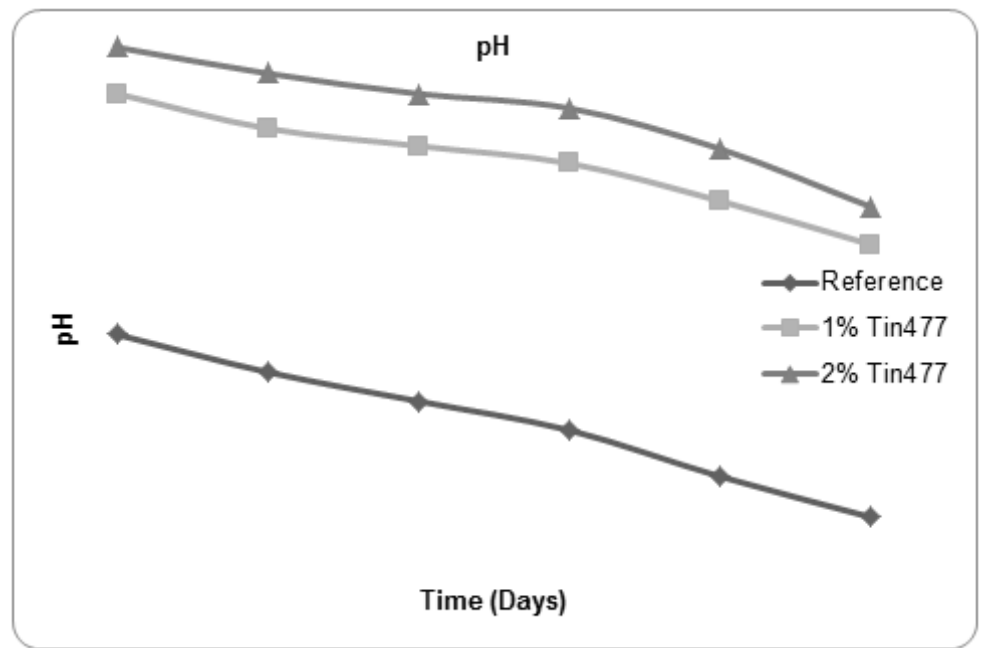

Fig-2: Plots of $\mathrm{pH}$ values vs time for the ink formulations with Tinuvin 477-DW

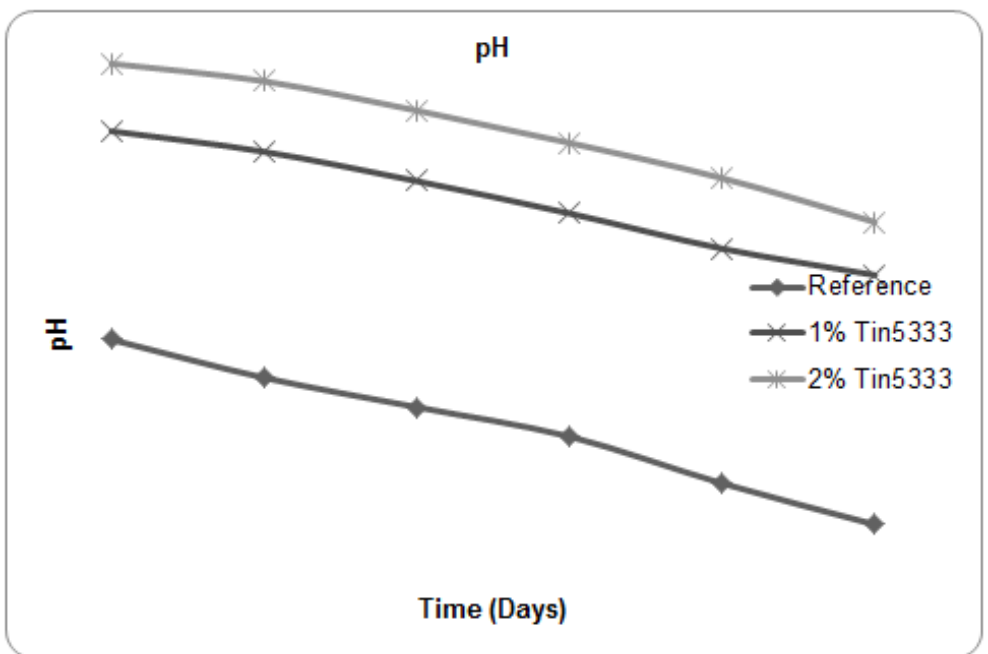

Fig-3: Plots of pH values vs time for the ink formulations with Tinuvin 5333-DW

Figures 4, 5 show the effect of storage time on the conductivity of the inks. The presence of Tinuvin 477-DW and Tinuvin 5333-DW results in a increase in conductivity values of both compared to the reference ink which already presents high conductivity values
(Figures 4, 5). This can possible be attributed to the presence of ionized amino groups which may give rise to higher conductivity values compared to the reference ink 1.1. Conductivity values are also proportional to the quantity of the agent used in both dye inks prepared.

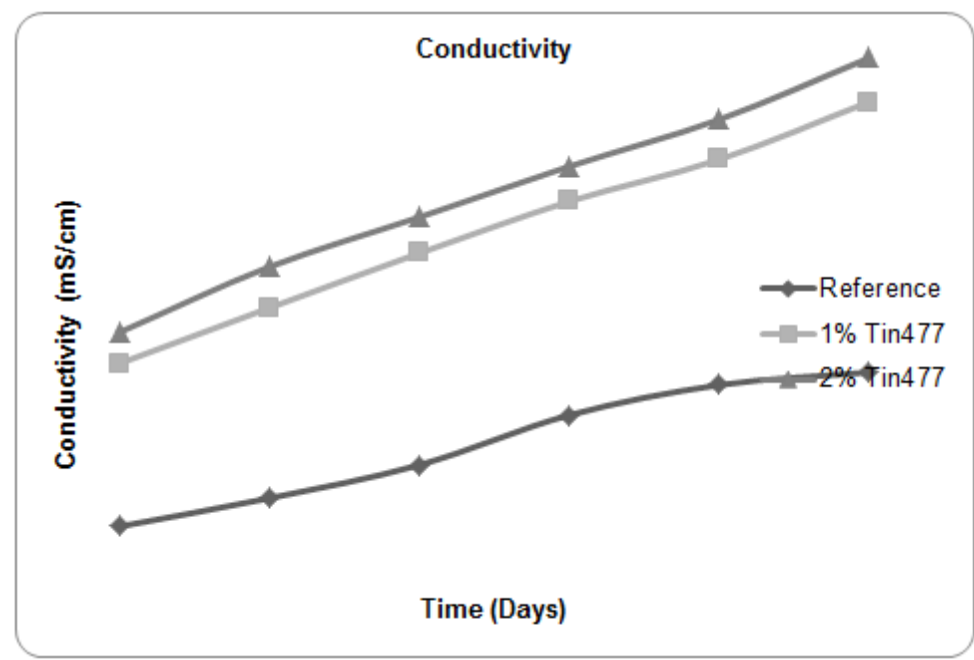

Fig-4: Plots of conductivity values vs time for the ink formulations with Tinuvin 477-DW 


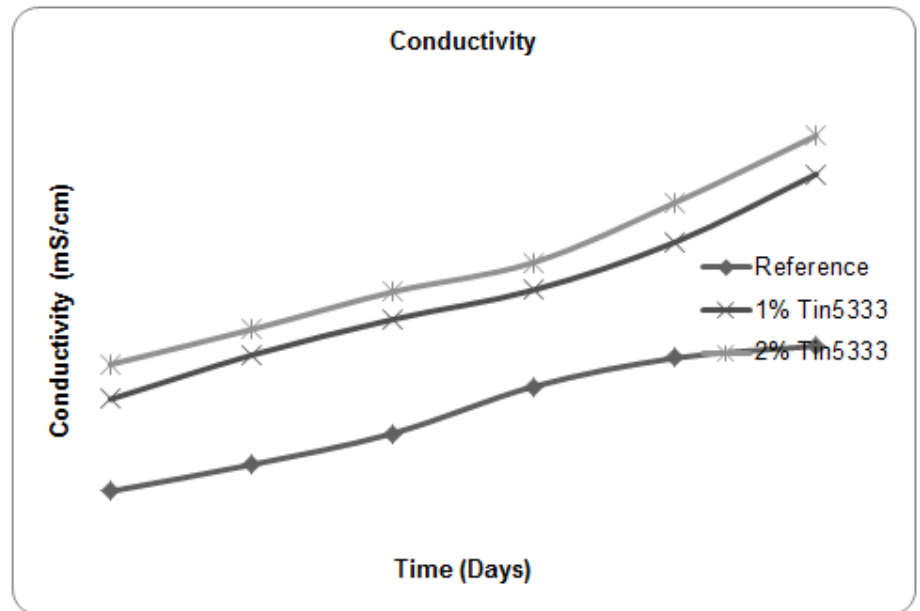

Fig-5: Plots of conductivity values vs time for the ink formulations with Tinuvin 5333-DW

Figures 6, 7 show the surface tension values of the inks prepared against storage time. All the surface tension values are increasing during the time storage. The addition of the two active agents causes a normal increase until day 28 which becomes sharper until the end of the measurements. This increase in surface tension which becomes sharper can be attributed to the higher surface activity conferred by the long hydrophobic chains of Tinuvin 477-DW and Tinuvin 5333-DW. Surface tension increase is at the benefit of the adhesional wetting of the ink. Typical surface tension values of commercial ink-jet inks for textile printing are in range $21-48$ or $30-60 \mathrm{mNm}^{-1}[3,17,18]$. The surface tension values of all inks prepared with and without the additives are in the acceptance range making them suitable for ink jet applications.

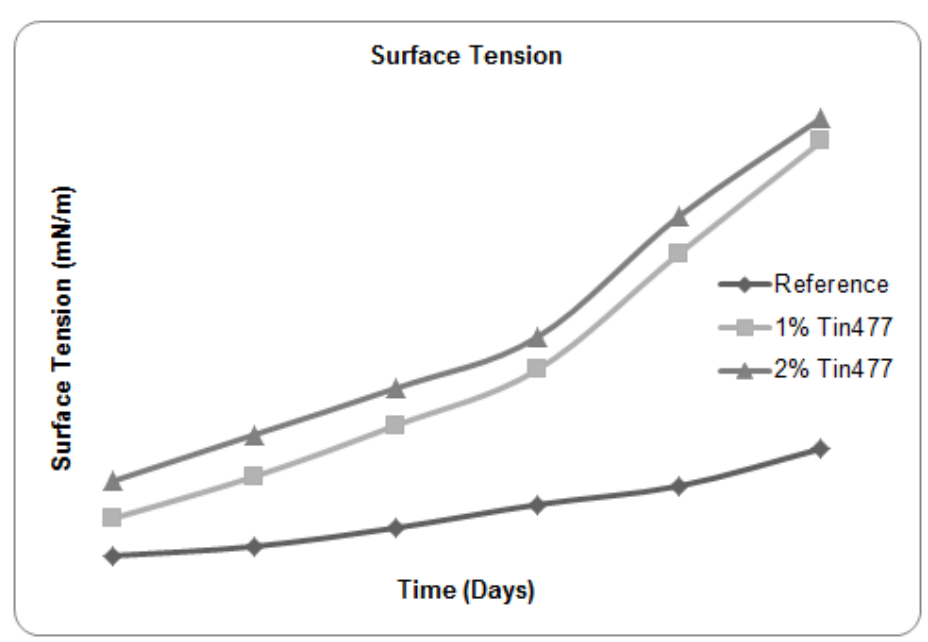

Fig-6: Plots of surface tension values vs time for the ink formulations with Tinuvin 477-DW

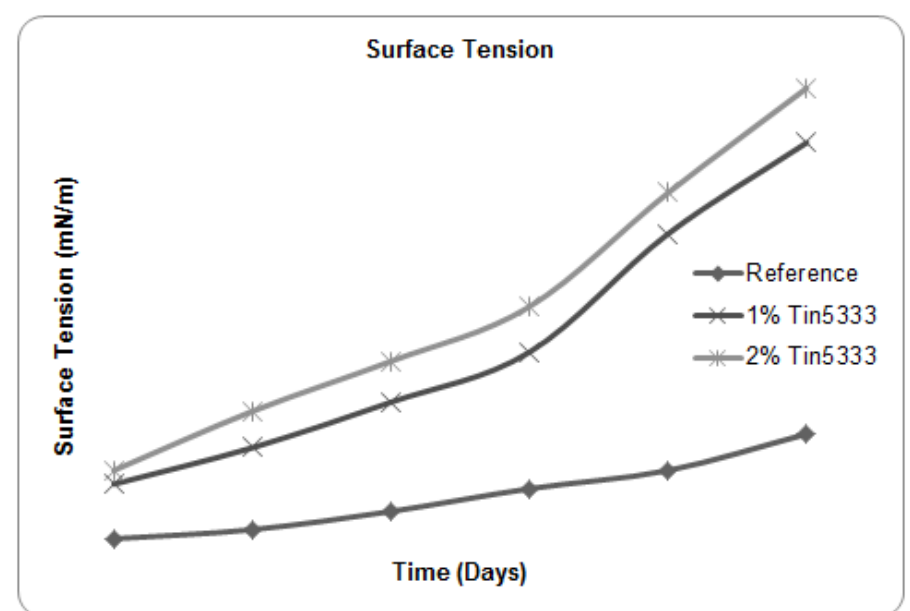

Fig-7: Plots of surface tension values vs time for the ink formulations with Tinuvin 5333-DW 
Figures 8, 9 show the effect of storage time on viscosity. It is generally accepted that ink-jet inks should have a viscosity lower than $2 \mathrm{cP}$ to be suitable for digital printing application although it is not so strange for such inks to have a viscosity up to $3 \mathrm{cP}[17,18]$. All inks with and without the active agents showed an intitial sharp increase in viscosity during the period of storage. This sharp increase can be attributed to the presence of the dispersing agent present in all inks, Alcosperse LFD, which is sodium salt of a polysulphonated derivative full dissociation of which produce more anionic repulsions and thus causing an increase in viscosity as a function of storage time. Also, the high viscosity $(10-50 \mathrm{cP})$ and the big density $\left(1,05 \mathrm{~g} / \mathrm{cm}^{3}\right)$ of the active agents is another reason why the inks have so big values viscosity $[19,20]$.

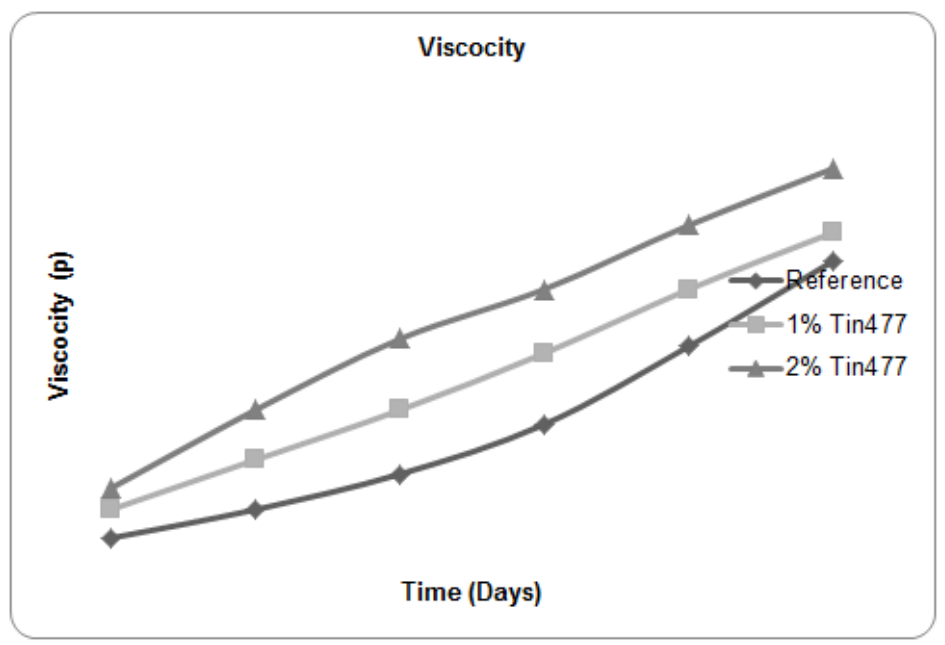

Figure 8: Plots of viscosity values vs time for the ink formulations with Tinuvin 477-DW

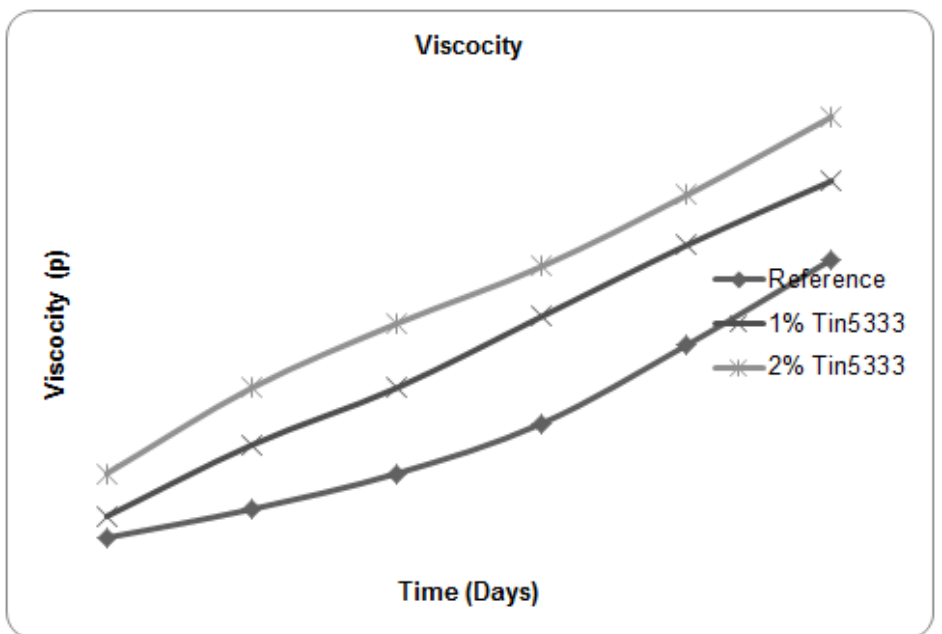

Fig-9: Plots of viscosity values vs time for the ink formulations with Tinuvin 5333-DW

\section{Fastness properties}

The wash light and rub fastness properties of the digitally printed polyester and polyamide samples are given in Table 2. The wash fastness for all printed samples after the reduction clearing treatment performed is excellent with no staining of the adjacent fibres of the multifibre strip (values 5) and no color change of the digitally printed samples (values 5). Rub fastness both wet and dry were excellent, (5 on grey scale) for both polyester printed samples with and without active agent.

Light fastness of the reference printed polyester (value 4-5) was medium, while reference polyamide sample presented a low (value 2) light fastness value. Addition of the UV-absorber in the ink formulations resulted, in almost all cases, an improvement in light fastness with range 0.5-1.5 units on the blue standard scale. Comparing the effectiveness on the light fastness of the two UV-absorbers, it is evident that both UV-absorbers had the same results. Nevertheless, the addition higher amount of active agent caused an improvement in light fastness (samples $1.3,1.5)$. Finally Table 2 showed that the light fastness on polyester were higher, due to the fact that disperse dyes are used especially for polyester dyeing and printing. 
Table-2: Fastness values of the printed samples with/without active agent

\begin{tabular}{|c|c|c|c|c|c|c|c|c|c|c|c|}
\hline \multirow[t]{2}{*}{ Sample } & \multirow[t]{2}{*}{ Fibre } & \multirow[t]{2}{*}{ Colour Change } & \multicolumn{6}{|c|}{ Wash Fastness } & \multirow[t]{2}{*}{ Light Fastness } & \multicolumn{2}{|c|}{ Rub Fastness } \\
\hline & & & Acetate & Cotton & Nylon & Polyester & Acrylic & Wool & & Dry & Wet \\
\hline 1.1 & PES & 5 & 5 & 5 & 5 & 5 & 5 & 5 & $4-5$ & 5 & 5 \\
\hline 1.2 & PES & 5 & 5 & 5 & 5 & 5 & 5 & 5 & 5 & 5 & 5 \\
\hline 1.3 & PES & 5 & 5 & 5 & 5 & 5 & 5 & 5 & 6 & 5 & 5 \\
\hline 1.4 & PES & 5 & 5 & 5 & 5 & 5 & 5 & 5 & 5 & 5 & 5 \\
\hline 1.5 & PES & 5 & 5 & 5 & 5 & 5 & 5 & 5 & 6 & 5 & 5 \\
\hline 1.1 & PA & 5 & 5 & 5 & 5 & 5 & 5 & 5 & 2 & 5 & 5 \\
\hline 1.2 & PA & 5 & 5 & 5 & 5 & 5 & 5 & 5 & $2-3$ & 5 & 5 \\
\hline 1.3 & PA & 5 & 5 & 5 & 5 & 5 & 5 & 5 & 3 & 5 & 5 \\
\hline 1.4 & PA & 5 & 5 & 5 & 5 & 5 & 5 & 5 & $2-3$ & 5 & 5 \\
\hline 1.5 & PA & 5 & 5 & 5 & 5 & 5 & 5 & 5 & 3 & 5 & 5 \\
\hline
\end{tabular}

\section{Colour measurements of digitally printed samples}

The ink formulations were applied to polyester and polyamide fibres by transfer printing followed by thermostabilization. Almost $100 \%$ transfer of the printed ink from the paper to the textile substrate is taking place under the transfer conditions employed. It is believed that the transfer of the ink from the paper to the textile substrate is being made not through a conventional sublimation transfer mechanism but through a melt or wet transfer mechanism where a thin layer from the digitally printed paper is being deposited on the polyester or polyamide substrate.

Table 3 shows the relevant colorimetric data and color strength values for the polyester and polyamide printings. $\mathrm{L}^{*}, \mathrm{a}^{*}, \mathrm{~b}^{*}, \mathrm{C}^{*}, \mathrm{H}^{*}$ co-ordinates and the K/S values were calculated from the reflectance values at the appropriate $\lambda \max (680 \mathrm{~nm}$ for C.I Disperse Blue 60). From table 3 the following are concluded:

The presence of two active ingredients in the digital ink formulation has resulted in a significant dye increase as this is expressed by the higher K/S values of the polyester prints containing Tinuvin 477-DW and Tinuvin 5333-DW compared to the reference (1.1). The "carrier action" of the Tinuvin 5333-DW seems to be higher than the Tinuvin 477-DW and this can be attributed to the absence of phenolic ring in the structure of Tinuvin 5333-DW which may act as dispersing agent more effectively than Tinuvin 477-DW increasing the solubility of the disperse dye in the aqueous phase and thus promoting higher dye uptake. The active ingredients, may be capable to form hydrogen bonds between their hydroxy group and the amine groups or the N-heteroatom of the disperse blue dye respectively and thus increasing the solubility of the sparingly soluble disperse dye in the aqueous face and thus possibly acting as a "carrier", promoting higher dye uptake by the polyester and polyamide fibre compared to the reference digital printing ink. This higher uptake was especially noticed with the bigger and bulkier blue disperse dye which possess two free amine groups and a long aliphatic chain in the molecule making the dye bulkier and more difficult to penetrate the rigid polyester fibre [21].

On polyamide application the inclusion of the active agents has the same effect as on polyester. The color strength of the polyamide prints is lower compared to polyester ones and this can be explained as also mentioned above that disperse dyes are the principal class for the dyeing and printing of polyester where they show good build up and to a lesser extent for polyamide application [22].

The $\mathrm{H}^{*}$ values of the prints both on polyester and polyamide are in the green-blue region of the color circle.

Table-3: Color coordinates $L^{*}, a^{*}, b^{*}, C^{*}, H^{*}$ and color strength $\mathrm{K} / \mathrm{S}$ values of the printings with/without active agent

\begin{tabular}{|l|l|l|l|l|l|l|l|l|}
\hline Sample & Fibre & $\lambda \mathbf{m a x}$ & $\mathbf{K} / \mathbf{S}$ & $\mathbf{L}^{*}$ & $\mathbf{a}^{*}$ & $\mathbf{b}^{*}$ & $\mathbf{C}^{*}$ & $\mathbf{h}^{\mathbf{0}}$ \\
\hline 1.1 & PES & $680 \mathrm{~nm}$ & 0.255 & 83.45 & -7.77 & -5.91 & 9.76 & 217.25 \\
\hline 1.2 & PES & $680 \mathrm{~nm}$ & 0.304 & 82.74 & -9.23 & -7.55 & 11.92 & 219.31 \\
\hline 1.3 & PES & $680 \mathrm{~nm}$ & 0.338 & 82.36 & -10.05 & -8.54 & 13.19 & 220.36 \\
\hline 1.4 & PES & $680 \mathrm{~nm}$ & 0.32 & 82.44 & -9.49 & -7.81 & 12.29 & 219.45 \\
\hline 1.5 & PES & $680 \mathrm{~nm}$ & 0.362 & 81.95 & -10.55 & -8.91 & 13.81 & 220.19 \\
\hline 1.1 & PA & $680 \mathrm{~nm}$ & 0.145 & 82.54 & -1.76 & 0.18 & 1.77 & 174.27 \\
\hline 1.2 & PA & $680 \mathrm{~nm}$ & 0.161 & 82.25 & -2.33 & -0.94 & 2.51 & 202.04 \\
\hline 1.3 & PA & $680 \mathrm{~nm}$ & 0.175 & 81.83 & -2.98 & -0.79 & 3.09 & 194.86 \\
\hline 1.4 & PA & $680 \mathrm{~nm}$ & 0.167 & 82.70 & -3.37 & -1.26 & 3.60 & 234 \\
\hline 1.5 & PA & $680 \mathrm{~nm}$ & 0.179 & 82.95 & -3.49 & -1.43 & 3.77 & 202.29 \\
\hline
\end{tabular}

\section{Determination of the UV-abs from the digitally printed samples}

Tables 4, 5 show the amounts of active UVabsorbers extracted from the printed polyester and polyamide samples after four extraction cycles with polyethylene glycol 200 as a solvent. The amount of extracted Tinuvin 5333-DW from polyester and polyamide was higher to the extracted amount of Tinuvin 477-DW. The extracted amount of active agents show that about $20 \%$ of active agent UV- 
absorber over mass of fabric is deposited by the digital printing head on the textile substrate. This amount is responsible for the UV protection activity of the digitally printed samples.

Table-4: Amount (mg/L) of Tinuvin 477-DW adsorbed on polyester (PES) and polyamide (PA) printed samples.

\begin{tabular}{|l|l|l|}
\hline & POLYESTER & POLYAMIDE \\
\hline Tinuvin 477-DW \% w/v & $\begin{array}{l}\text { AMOUNT } \\
\text { mg/L }\end{array}$ & $\begin{array}{l}\text { AMOUNT } \\
\text { mg/L }\end{array}$ \\
\hline 1.0 & 253 & 108 \\
\hline 2.0 & 471 & 213 \\
\hline
\end{tabular}

Table-5: Amount (mg/L) of Tinuvin 5333-DW adsorbed on polyester (PES) and polyamide (PA) printed samples.

\begin{tabular}{|l|l|l|}
\hline Tinuvin 5333-DW \% w/v & $\begin{array}{l}\text { POLYESTER } \\
\text { AMOUNT } \\
\text { mg/L }\end{array}$ & $\begin{array}{l}\text { POLYAMIDE } \\
\text { AMOUNT } \\
\text { mg/L }\end{array}$ \\
\hline 1.0 & 316 & 143 \\
\hline 2.0 & 545 & 292 \\
\hline
\end{tabular}

\section{CONCLUSIONS}

The UV-absorber Tinuvin 477-DW and Tinuvin 5333-DW were successfully incorporated in water based ink-jet inks prepared for the ink-jet printing of polyester and polyamide fabrics. The physical properties $\mathrm{pH}$, surface tension, conductivity and viscosity of the inks were monitored over a period of 90 days and their stability for ink -jet printing was confirmed. The inks were used for the digital printing of paper, transfer on polyester and polyamide fabrics and thermostabilization. Color, wash, rub and light fastness measurements of the prints were made and presented. Quantitative determination of the two agents adsorbed on the fibre was also made and the results regarding the UV protection activity of the textiles were excellent. Addition of the UV-absorbers in the ink formulations resulted, in almost all cases, in an improvement in light fastness. Comparing the effectiveness on the light fastness of the two UV-absorbers, it is evident that both of them had the same results on the synthetic printed samples.

\section{ACKNOWLEDGEMENTS}

This research is co-financed by Greece and the European Union (European Social Fund- ESF) through the Operational Programme «Human Resources Development, Education and Lifelong Learning» in the context of the project "Reinforcement of Postdoctoral Researchers - 2nd Cycle" (MIS-5033021), implemented by the State Scholarships Foundation (IKY).

\section{REFERENCES}

1. Fryberg, M. (2005). Dyes for ink-jet printing. Review Progress Coloration. 35(1), 1-30.

2. Daplin, S., \& Lin, L. (2003). Evaluation of pigmented ink formulations for jet printing onto textile fabrics. Pigment and Resin Technology. 32(5), 307-318.

3. Holme, I. (2004). Digital ink jet printing of textiles. Textile Magazine. 1, 11-16.

4. Provost, J. (1994). Surf Coat Int (JOCCA), 77(1), 36.
5. Cahill, V. (2004). 'Digital Textile Printing 2004' Presentation. (VCE Solutions, Philadelphia University IS \& T NIP 20, Salt Lake City, UT).

6. Tyler, D. (2005). Textile digital printing technologies. Textile Progress, 37(4), 1-65.

7. Ujiie, H. (2006). Digital Printing of Textiles. (Woodhead Publishing, Campridge).

8. Kang, H. R. (1991). Water based ink jet ink. II. Characterization. Journal Imaging Science Technology. 35, 189-194.

9. Yamanoto, T., Haruta, M., Koike, S., Shirota, K., Yoshihira, A., \& Suzuki M. (1997). Textile printing method, printed textile obtained thereby, and ink SI Patent, no. 8910720.

10. Kehayoglou, A. H., \& Tsatsaroni, E. G. (1993). Dyeing of polyester fabrics with disperse dyes in the presence of a UV-absorber. Dyes \& Pigmemts, 23(1), 53-63.

11. Baumann, J. (1985). Textilveredlung. 20, 356.

12. Eichler, R., Richter, P., \& Vonhoene, P. (1985). Textilveredlung. 20, 126.

13. Reinert, J. (1991). Textilveredlung, 26(3), 86.

14. Methods of Test for Colour Fastness of Textiles and Leather. (1990). Bradford: Society of Dyers and Colourists.

15. Printing \& Packaging Tinuvin 477-DW Technical Data Sheet Industrial Coatings, (BASF The chemical company).

16. Technical Information Tinuvin 5333-DW, (BASF The chemical company).

17. Schulz, G. (2003). Melliand Textilberichte. 83, 154.

18. Siemensmeyer, K., \& Dorer, M. (1993). Melliand Textilberichte, $79,867$.

19. Printing and packaging industrial coating. (2010). (BASF corporation).

20. Leach, R. (2012). The printing ink manual. Springer Science \& Business Media.

21. Arcoria, A., Longo, M. L., \& Parisi, G. (1985). Effects of the phenol on the dyeing of polyester fibre with some disperse azo-dyes. Dyes \& Pigmemts, 6(2), 155-161.

22. Iskender, M., Bacevir, B., \& Kurujucu, A. (2005). Textile Research Journal, 75(6), 462. 